\title{
ESPACIALIDADE INFANTIL: ANÁLISE DAS PRÁTICAS ESPACIAIS E DOS VÍNCULOS ENTRE AS CRIANÇAS NA PRAÇA 7 DE SETEMBRO EM CRUZÍLIA - MG
}

\author{
Paloma Pereira Ramiro, Victor Martins De Aguiar, Yeda Ruiz Maria \\ Universidade do Oeste Paulista - UNOESTE, Presidente Prudente, SP. E-mail: paloma.ramiro007@gmail.com
}

\section{RESUMO}

Os espaços públicos são os principais agentes de criação das mais diversas relações que o ser humano pode estabelecer, sobretudo durante a primeira infância, onde são formados os primeiros vínculos responsáveis pela construção de uma memória e de um pertencimento ao espaço. Contudo, observa-se cada vez mais o descaso com estes espaços, consequentemente notando-se o abandono e o afastamento das crianças com o meio urbano, por conta da falta de infraestrutura e pelo não atendimento das demandas básicas de cultura e lazer voltadas para esse grupo. A pesquisa científica teve o intuito de analisar a relação entre as crianças e os espaços públicos e o objeto de estudo adotado foi a Praça 7 de Setembro, inaugurada em 1968 na cidade de Cruzília - MG. Por meio de levantamentos in loco, foram realizadas análises qualitativas e quantitativas acerca da infraestrutura ofertada aos usuários, como também análises das demandas e práticas espaciais da praça. Além disso, foram realizadas leituras sobre as políticas públicas urbanas ligadas à primeira infância no município e sobre o processo de desapropriação de uma parte da praça, em 2011, resultado da implantação de uma farmácia do Programa Farmácia de Minas, gerida pela Secretaria de Estado de Saúde de Minas Gerais (SES/MG). A metodologia empregada na pesquisa, portanto, consistiu na realização de revisões bibliográficas e documentais, levantamentos in loco e análises referentes ao objeto de estudo, a Praça 7 de Setembro, demonstrando a relevância das discussões acerca dos espaços públicos e o fortalecimento do vínculo de pertencimento da criança versus cidade.

Palavras-chave: Infraestrutura, Espaço Público, Praça, Pertencimento, Cruzília - MG.

\section{CHILDREN'S SPATIALITY: ANALYSIS OF THE SPATIAL PRACTICES AND THE LINKS BETWEEN CHILDREN IN THE 7 DE SEPTEMBER SQUARE IN CRUZÍLIA - MG}

\begin{abstract}
Public spaces are the main agents for the creation of the most diverse relationships that human beings can establish, especially during early childhood, where the first links responsible for building a memory and belonging to space are established. However, it is increasingly observed the neglect of these spaces, consequently noting the abandonment and distancing of children from the urban environment, due to the lack of infrastructure and the failure to meet the basic demands of culture and leisure aimed at this group. The scientific research aimed to analyze the relationship between children and public spaces and the object of study adopted was Praça 7 de Setembro, inaugurated in 1968 in the city of Cruzília - MG. Through on-site surveys, qualitative and quantitative analyzis were carried out on the infrastructure offered to users, as well as analyzes of the demands and spatial practices of the square. In addition, readings were carried out on urban public policies related to early childhood in the city and on the process of expropriation of a part of the square, in 2011, as a result of the implementation of a pharmacy of the Minas Pharmacy Program, managed by the State Secretariat of Minas Gerais Health (SES/MG). The methodology used in the research, therefore, consisted of conducting bibliographic and documental reviews, on-site surveys and analyzes regarding the object of study, Praça 7 de Setembro, demonstrating the relevance of discussions about public spaces and strengthening the bond of belonging of child versus city.
\end{abstract}

Keywords: Infrastructure, Public Space, Square, Belonging, Cruzília - MG. 


\section{INTRODUÇÃO}

Assim como as relações entre espaços públicos e crianças são de suma importância, também é necessário analisar o papel urbano no desenvolvimento da Primeira Infância, período compreendido entre 0 e 6 anos. A cidade é um dos maiores precursores das relações humanas, onde acontece o desenvolvimento das relações sociais e a criação de uma memória coletiva, por meio da própria história da cidade, sendo ainda um dos principais elementos educadores da sociedade. A expansão urbana desenfreada, sem planejamento e demasiadamente desconexa resultou na criação de espaços habitacionais sem uma infraestrutura adequada, sobretudo pela ausência de espaços públicos de qualidade. As demandas infantis também sofreram os impactos desse crescimento acelerado, limitando-se os espaços de lazer e o acesso a serviços básicos de saúde e educação adequados (LOEB, 2019).

Desse modo, é possível perceber que uma cidade que não oferece apoio às necessidades básicas de uma população, acaba contribuindo para um desenvolvimento infantil de baixa qualidade, com carência de infraestruturas e problemáticas sociais sem a devida atenção. Loeb (2019) também pontua sobre a falta de políticas públicas voltadas ao público infantil, resultando em espaços públicos sem qualquer atrativo, que não atendem às mínimas necessidades e, muitas vezes, não são frequentados em razão da insegurança. Tais problemáticas favorecem $\mathrm{o}$ aumento de diferenças econômicas, étnicas e sociais.

Além de serem os mais efetivos locais de socialização e trocas de experiências, os espaços públicos são demasiadamente importantes para o desenvolvimento infantil, devido ao contato com o meio externo e as vivências propiciadas pela urbe, como expõe Meira (2011). Essa inquietação tem acarretado a produção dos mais variados trabalhos ${ }^{1}$, relacionados à temática da conexão entre criança e cidade, com o intuito de ser um local propício para um crescimento promissor. Ainda dentro desse contexto, muitos autores relatam e analisam a relação de esquecimento perante o papel da criança no âmbito urbano,

\footnotetext{
1 Alguns dos principais trabalhos desenvolvidos sobre o tema são: Olhares das crianças sobre a cidade de Porto Alegre: infância contemporânea, psicanálise, educação e arte (MEIRA, 2011); O uso dos espaços urbanos pelas crianças: explorando o comportamento do brincar em praças públicas (LUZ; KUHNEN, 2013); Espaços públicos: suas potencialidades educadoras e a construção da cidadania (MERLIN; QUEIROZ, 2014).
}

sobretudo através da perspectiva das cidades educadoras ${ }^{2}$, cuja função é que a criança seja o principal agente de transformações e qualificações.

Os primeiros espaços públicos, denominados como praças e parques, surgiram a partir do século $X X$, atendendo assim às demandas decorridas das transformações nos âmbitos espaciais, econômicos e socioculturais das cidades. Neste momento, a rua deixa de ser um ambiente tranquilo, e se torna sinônimo de perigo, sobretudo em função da mobilidade urbana, em virtude dos automotores. Constata-se assim, que os atuais espaços públicos de lazer não atendem as mais básicas necessidades de seus usuários e, diferentemente do objetivo inicial de sua criação, que era o de oferecer um espaço de lazer e de trocas sociais, hoje vêm se convertendo em locais inseguros e abandonados (LUZ; KUHNEN, 2013).

Como já abordado, os espaços públicos são os principais locais de fomento às demandas de experimentação e socialização de uma criança, pois é o lugar onde se inicia a integração com outras crianças, com adultos e com o meio urbano. A participação efetiva das crianças, por meio do reconhecimento de seu potencial imaginário, é um fator que pode transformar o modo como as cidades são construídas, assumindo o local da criança como cidadã e também capaz de solucionar as problemáticas da cidade. Jorge Raédo ${ }^{3}$ (2018) é um dos muitos que acredita no poder que unir arquitetura, educação e infância pode resultar na construção de uma cidade mais socialmente justa:

Quando uma criança se
aproxima da arquitetura
enquanto linguagem, ela
também se aproxima do
urbanismo,
compreendendo porque
sua cidade é feita do jeito
que é, com uma rua ali,
uma praça aqui. Os
projetos escolhidos

\footnotetext{
De acordo com a Asociación Internacional de Ciudades Educadoras (2012), as cidades são educativas por si, mas elas tornam-se educadoras quando assumem essa intenção "consciente de que suas propostas têm consequências em atitudes e convivências e geram novos valores, conhecimentos e habilidades". ${ }^{3}$ Educador e artista espanhol, idealizador do evento Ludantia - I Bienal Internacional de Educação em Arquitetura para Infância e Juventude, realizado em parceria com Xosé Manuel Rosales Noves e Virginia Navarro Martínez, na cidade de Potevedra, na Espanha, em 2018 (GARCIA, 2018).
} 


\begin{abstract}
incentivam sua participação na decisão democrática de como funciona o lugar onde ela mora. Afinal, esse deveria ser o objetivo final de qualquer processo educativo: o da integração e entrada da criança dentro da comunidade (RAÉDO, 2018 apud Garcia, 2018, não paginado.).
\end{abstract}

Sendo assim, é de suma importância que os espaços ofereçam uma infraestrutura de qualidade, a fim de auxiliar no desenvolvimento de seus usuários. Porém, o cenário observado nas últimas décadas é bastante diferente do ideal para esses espaços, que são cada vez mais carentes de atrativos. Além de não atenderem as demandas dos pequenos usuários, observam-se espaços públicos cada vez mais inadequados para o total uso das crianças. Algumas das principais problemáticas verificadas são a falta de segurança e desconforto dos equipamentos ofertados, diminuindo a autonomia e independência no momento das brincadeiras cotidianas. Essas problemáticas podem ainda resultar em acidentes, não só dentro dos espaços públicos, mas também em seu entorno, principalmente acidentes no trânsito, como afirmam Luke et al. (2021).

Tais fatores, infelizmente, acabam resultando no afastamento entre criança $e$ cidade, o que também auxilia no esquecimento do papel infantil no desenvolvimento urbano, em razão do "desaparecimento" das crianças nos equipamentos públicos, conforme Rocha et al. (2018). Outros motivos para este afastamento se devem ao fato dos novos meios de comunicação e o vasto acesso à internet, em que cada vez mais se verifica o uso exacerbado de equipamentos eletrônicos, substituindo as práticas sociais estabelecidas em locais públicos.

Um terceiro fator para esse afastamento se deve, conforme denomina Sarmento (2019, de um deslocamento "casa-escola-shopping", responsável por causar o isolamento das crianças do meio urbano, bem como dos espaços públicos, tão importantes para o desenvolvimento infantil. Somadas, essas condições de afastamento determinam a necessidade de incentivar o uso de espaços públicos, por meio de soluções que atraiam os públicos mais jovens, tanto no sentido do pertencimento, como na própria oferta de segurança (GADELHA, 2019).

É também importante salientar a função dos governos, sendo na esfera municipal, estadual ou federal, quanto às políticas públicas que garantam o pleno acesso a todos os direitos constitucionalmente assegurados à infância. Um dos mais relevantes estudos sobre o caso, é o Estatuto da Criança e do Adolescente - ECA, segundo a lei № 8.069/1990, que reúne um conjunto de leis e diretrizes que salvaguardam os direitos da população da faixa etária compreendida entre 0 e 18 anos de idade. Como consta no artigo № 3 do Estatuto da Criança e do Adolescente, a criança e o adolescente gozam de todos os direitos fundamentais inerentes à pessoa humana, sem prejuízo da proteção integral de que trata esta lei, assegurando-seIhes, por lei ou por outros meios, todas as oportunidades e facilidades, a fim de lhes facultar o desenvolvimento físico, mental, moral, espiritual e social, em condições de liberdade e de dignidade.

Outro significativo documento, que visa garantir os direitos do cidadão perante o meio urbano, é o Estatuto da Cidade, lei № $10.257 / 2001$, o qual também agrupa diversas diretrizes com relação à construção de novos parcelamentos de solo e a expansão das cidades, visando à promoção da sustentabilidade e da acessibilidade e, garantindo aos habitantes o acesso às infraestruturas básicas com o objetivo de proporcionar maior qualidade de vida. Contudo, em ambos os estatutos, observa-se pouca ou inexistente discussão acerca da criança nos espaços públicos urbanos e não existem diretrizes específicas elaboradas para esta temática.

Na maioria dos municípios, do mesmo modo, é demasiadamente escassa a existência de políticas públicas com direcionamentos exclusivos para as crianças, evidenciando a ausência da participação desse público e a atenuação da cidadania infantil. Na cidade de Cruzília - MG, em que se localiza a praça objeto de estudo, o Plano Diretor, lei № 1.908/2009, cita as crianças em seu capítulo $\mathrm{V}$, garantindo acesso à educação, e em seu capítulo VII, sobre o acesso aos esportes e ao lazer, porém não possui nenhuma especificação ou orientação sobre a atuação do plano diretor junto ao público infantil ou sobre as iniciativas necessárias para o atendimento das demandas desse público.

Em 5 de outubro de 2016, foi instituído, a 
nível federal, o Programa Criança Feliz, sob o decreto № 8.869, com a finalidade de promover o desenvolvimento integral das crianças na primeira infância. A participação no programa é facultativa e ocorre por meio de procedimento de adesão de cada município, que precisa obrigatoriamente conter ao menos 01 (um) Centro de Referência de Assistência Social - CRAS e no mínimo 140 pessoas que atendam aos critérios de participação do programa, que atualmente está presente em quase 3.000 (três mil) municípios em todo o Brasil (BRASIL, [2019?]).

No mesmo ano de criação do Programa, o mesmo foi aderido por Cruzília, por meio da Câmara Municipal, juntamente com o Centro de Referência de Assistência Social - CRAS, conforme dados da Prefeitura Municipal de Cruzília (2021). Os pilares do Programa consistem na realização de visitas domiciliares, a fim de constatar as reais necessidades da criança e de sua família, e na integração das políticas públicas de saúde, educação, assistência social, cultura e promoção e defesa dos direitos da criança no âmbito do município. Contudo, ainda há poucos dados sobre a efetivação do programa em Cruzília, além do mesmo não contemplar diretamente diretrizes para o desenvolvimento urbano infantil. Por ser uma adesão setorial e facultativa, muitas cidades ainda não aderiram ou não são elegíveis para o programa, dificultando a promoção desses cuidados específicos para as crianças.

Em razão da falta de políticas públicas urbanas relacionadas à criança, a cidade pode interferir negativamente na vida de toda a população, principalmente no âmbito infantil, dificultando o desenvolvimento pleno dos primeiros aprendizados e experiências das crianças. Apesar disso, ela tem um papel fundamental nas questões educacionais e sociais, sendo palco das primeiras interações com os meios externos. Merlin e Queiroz (2014) evidenciam a função educadora da cidade, que se dá através da demasiada gama de pessoas, atividades e informações com que diariamente se tem contato nos mais diversificados locais dentro do meio urbano, sobretudo nos espaços públicos, locais da mais intensa troca de experiências e socializações.

Com base nesse aporte teórico/conceitual, observa-se a relevância no papel da infância contemporânea na concepção de novos espaços públicos urbanos, bem como a reestruturação e reformação de espaços públicos existentes, tendo como premissa os ideais de equidade e acessibilidade, gerando assim uma cidade mais inclusiva (GADELHA, 2019). Com base nessa perspectiva, a pesquisa analisou a relação da criança com o espaço público, estabelecendo como objeto de estudo a Praça 7 de Setembro, na cidade de Cruzília - MG.

\section{MÉTODOS}

A pesquisa foi realizada por meio de revisões bibliográficas, através do emprego de materiais científicos, artigos e monografias que abarcam as questões referentes à relação entre as crianças e os espaços públicos. Parte da pesquisa, bem como as análises foram desenvolvidas de forma remota, através de conteúdo online, documentos e trabalhos disponibilizados digitalmente e com recursos como o Google Maps e Google Earth, com o intuito de fundamentar e propiciar as informações necessárias para sua realização.

Para a real constatação das informações acerca da Praça 7 de Setembro, recorte espacial de estudo da pesquisa, foi necessária a utilização de materiais teóricos da cidade de Cruzília - MG, como leis, decretos e documentos, obtidos por meio do site da prefeitura municipal e em plataformas digitais. Além das informações coletadas por meios eletrônicos, foi também necessário o levantamento in loco da Praça 7 de Setembro ${ }^{4}$, onde foram realizadas análises acerca da infraestrutura encontrada no espaço público e, posteriormente, caracterizadas quantitativa e qualitativamente, que apresentadas no corpo desta pesquisa, por meio de informações textuais, imagens ${ }^{5}$ e gráficos.

Durante a realização dos levantamentos in loco, foi elaborada uma tabela para a organização das informações, subdivididas em arborização, iluminação, áreas verdes, áreas pavimentadas, mobiliários (como exemplo bancos e lixeiras), mobiliários esportivos, infantis e educativos. Além das características referentes à infraestrutura da praça, também se observou as relações de uso do espaço público, sobretudo aquelas ocorridas entre as crianças, fomentando as análises sobre os períodos de uso, as atividades realizadas e as condições ofertadas

\footnotetext{
${ }^{4}$ Realizados seguindo todos os protocolos de biossegurança contra a transmissão do vírus da Covid-19, conforme recomendação da Universidade do Oeste Paulista - UNOESTE e da Organização Mundial da Saúde - OMS.

${ }^{5}$ Todas as imagens utilizadas foram devidamente editadas a fim de preservar a identidade das pessoas, de acordo com os direcionamentos abordados pelo Comitê de Ética da Universidade.
} 
para sua realização, cujas análises também estão apresentadas em meios textuais e visuais.

Os métodos, portanto, foram pautados em discussões teóricas e conceituais, dando subsídios à pesquisa, bem como em discussões práticas, que fomentaram as análises acerca da praça e das práticas espaciais estabelecidas principalmente com as crianças. Por fim, na conclusão da pesquisa são propostas as diretrizes projetuais para a melhoria da Praça 7 de Setembro, com a finalidade de que potencialize o uso e desenvolvimento das crianças.

\section{RESULTADOS}

Cruzília é um município situado na mesorregião do sul/sudoeste do estado de Minas
Gerais (Figura 01), distante 327 km da capital Belo Horizonte, em uma área de $522.429 \mathrm{~km}^{2}$, com população de cerca de 14.591 habitantes, de acordo com o último censo realizado em 2010 pelo Instituto Brasileiro de Geografia e Estatística (IBGE, 2010). O município integra o Circuito Turístico das Montanhas Mágicas da Mantiqueira e o Circuito das Águas de Minas Gerais, conhecida por suas fazendas centenárias, sua indústria de móveis e queijos premiados ao redor do mundo, também é considerado o berço dos cavalos da raça Mangalarga Marchador (CIRCUITO DAS ÁGUAS MG[c2021]).

Figura 01. Localização de Cruzília no Estado de Minas Gerais e delimitação do perímetro urbano.

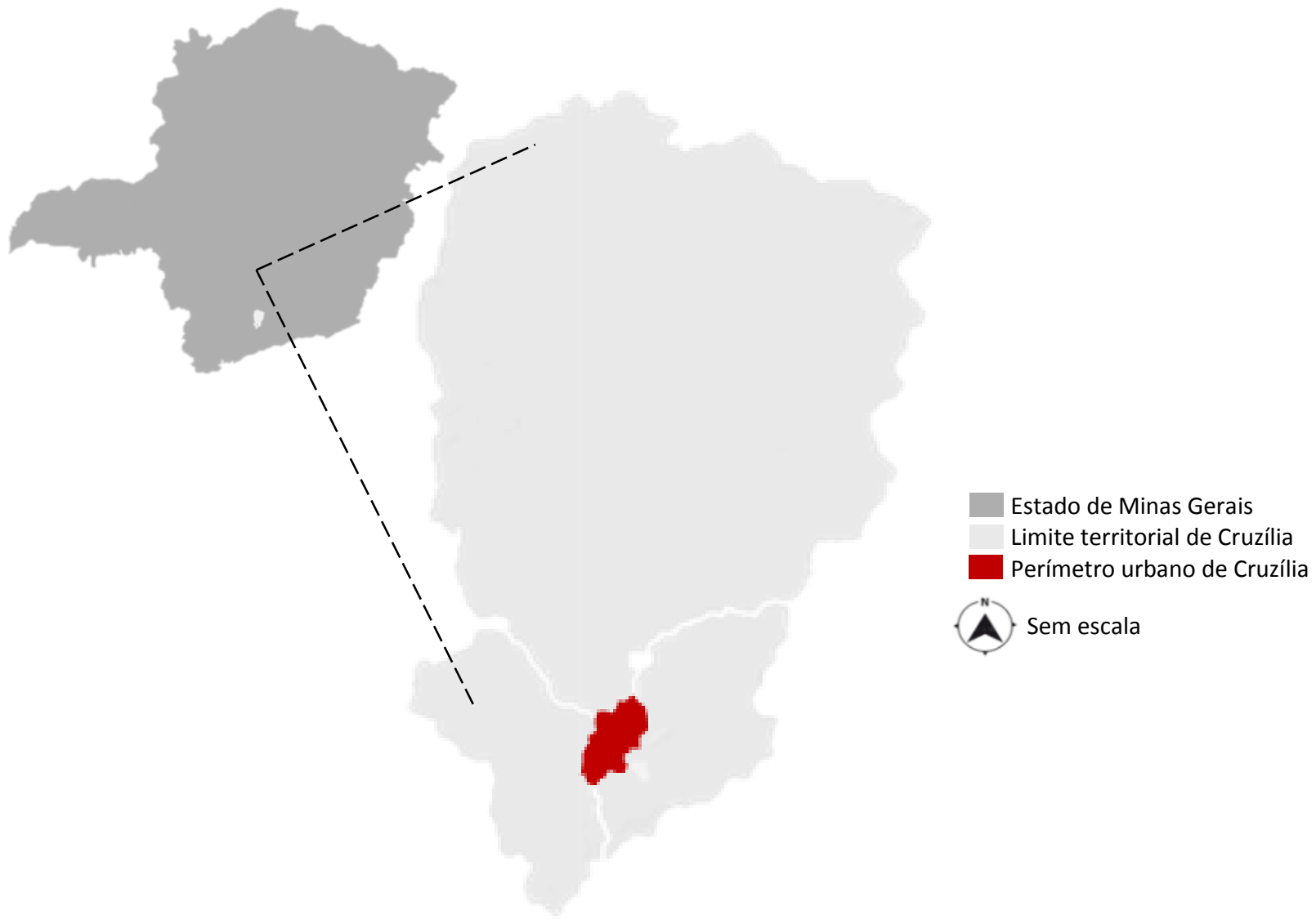

Fonte: Google Earth (2020), editado pelos autores (2021).

A cidade pertence ao Caminho Velho da Estrada Real (Figura 02), juntamente com o Caminho Novo, o Caminho dos Diamantes e o Caminho Sabarabuçu, formando a maior rota turística do Brasil, com mais de $1.630 \mathrm{~km}$ de extensão, entre os estados de São Paulo, Rio de
Janeiro e Minas Gerais ${ }^{6}$. Este trajeto surgiu em meados do século XVIII, devido ao transporte de

\footnotetext{
${ }^{6} \mathrm{O}$ Instituto Estrada Real é uma entidade sem fins lucrativos, criada em 1999 e pelo Sistema Federação das Indústrias do Estado de Minas Gerais (FIEMG). É responsável pelo fomento e organização de ações referentes à Estrada Real, elucidando todo o percurso, pontos turísticos, riquezas gastronômicas, culturais e naturais da região (Disponível http://www.institutoestradareal.com.br/estradareal. Acesso em: 14 julh. 2021).
} 
diamantes e ouro provenientes de Minas Gerais, que levados aos portos do Rio de Janeiro eram destinados a Portugal, e inclusive foi oficialmente a primeira via aberta pela Coroa Portuguesa com essa finalidade (INSTITUTO ESTRADA REAL, s.d.).

Figura 02. Localização de Cruzília no Caminho Velho da Estrada Real.

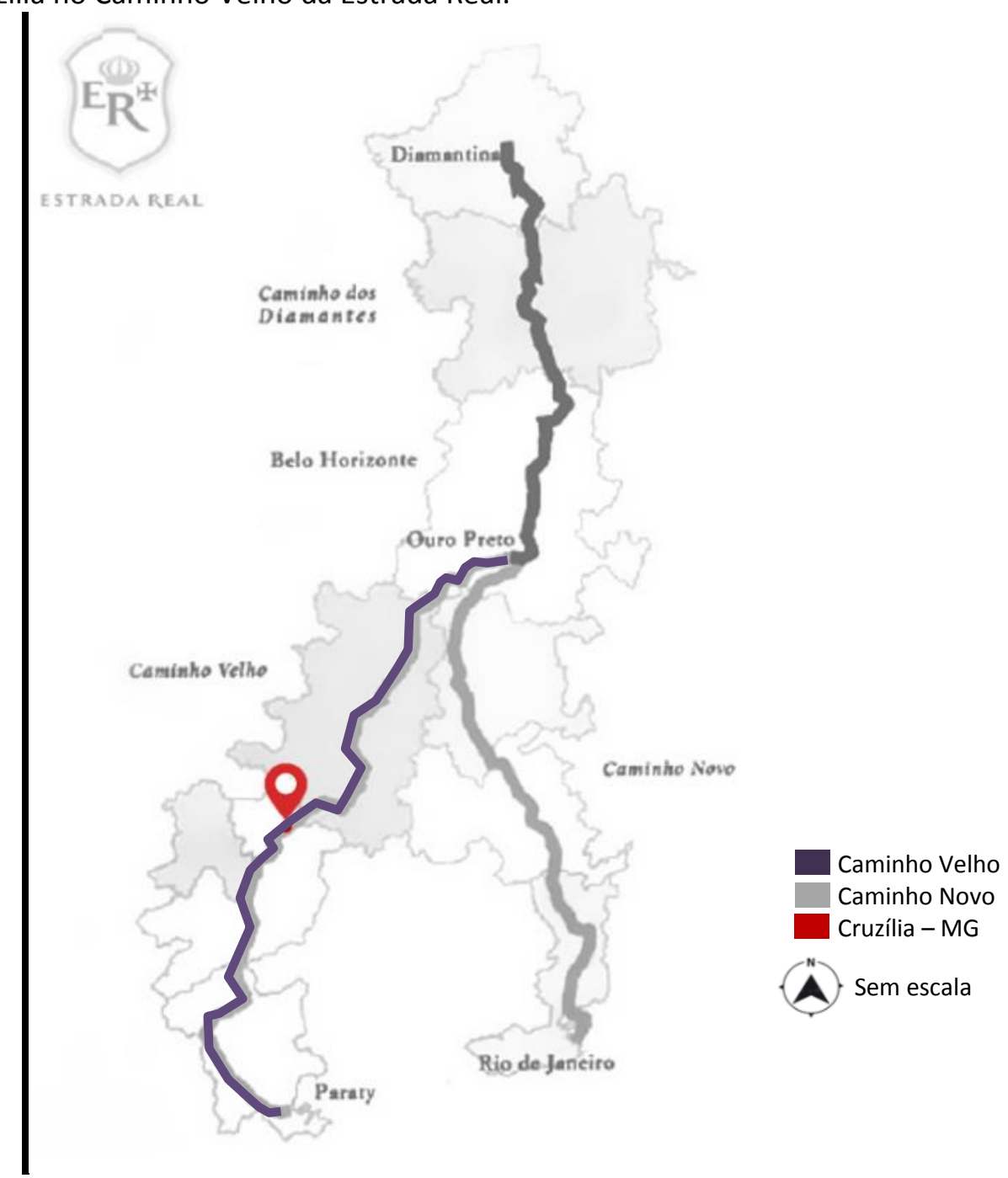

Fonte: Instituto Estrada Real (2020), editado pelos autores (2021).

$\mathrm{O}$ primeiro nome dado à cidade, até então um povoado, foi Encruzilhada, em 1873, derivado de sua localização, já que a região estava próxima à encruzilhada de duas importantes estradas no período colonial, que interligavam os municípios de Aiuruoca e São João Del Rei e Rio de Janeiro à região aurífera mineira (PREFEITURA MUNICIPAL DE CRUZÍLIA, 2021). Em 1920, tornouse São Sebastião da Encruzilhada, por conta de sua expansão nos arredores da Capela, que tinha como orago São Sebastião. O desenvolvimento desse aldeamento ocorreu oficialmente a partir de 1726, quando Manoel de Sá recebeu a sesmaria do Governador das Minas D. Lourenço de Almeida, porém há relatos de uso das terras da região desde o início dos anos 1600 (PEREIRA; PARISI, 2015). Até mesmo Carlos Drummond de Andrade se encantou com as riquezas da cidade e, no ano de 1973, escreveu a crônica "A Pequenina Cruzília", publicada no Jornal do Estado de Minas Gerais e no Jornal do Brasil:

[...] Era uma encruzilhada, no caminho de São Paulo para as Minas, no começo do século XVIII. Nessa encruzilhada se fixaram alguns moradores, sob a proteção de São Sebastião. o sítio virou arraial, e o 
arraial virou município, já agora sem o lindo nome de São Sebastião da Encruzilhada, pois uma das constantes da vida municipal do Brasil é trocar de nomes. Hoje se chama Cruzília (ANDRADE, 1973, Não paginado.).

O pequeno vilarejo passou a fazer parte do município de Baependi, conforme a lei № 1.997, em 14 de novembro de 1873. No entanto, em 27 de novembro de 1948, a partir da lei № 336, a vila já denominada Cruzília, que significa "terra da cruz", tornou-se um município mineiro em virtude do seu crescimento acelerado (PEREIRA; PARISI, 2015). A história colonial de Cruzília tem bastante destaque, sobretudo por ser a região mineira com as mais antigas fazendas de agricultura e pecuária do período, tendo em vista seu terreno mais plano, propício às fazendas agropecuárias. Dentre essas fazendas, uma delas, a Fazenda Bela Cruz, construída em 1855, teve sua sede, na área central de Cruzília (Figura 03), transformada em novembro de 2012, no Museu Nacional do Mangalarga Marchador (Figura 04), situado ao lado da Igreja Matriz (Figura 04) (PREFEITURA MUNICIPAL DE CRUZÍLIA, 2021).

Além da história colonial, o cenário esportivo de Cruzília é bastante conhecido. No futebol, a cidade tem visibilidade pelos campeonatos internos e disputas regionais, em que um dos principais times da cidade é o Clube 7 de Setembro, time centenário e ganhador de 8 ligas regionais. O Clube possui seu próprio estádio e sistema de lazer (Figura 05), onde em frente a uma das entradas, encontra-se a Praça 7 de Setembro, objeto de estudo da pesquisa (PREFEITURA MUNICIPAL DE CRUZÍLIA, 2021).

Figuras 03, 04 e 05- Localização da Praça 7 de Setembro, Museu Nacional do Cavalo Mangalarga Marchador, Igreja Matriz de São Sebastião e Estádio 7 de Setembro Futebol Clube em Cruzília - MG.

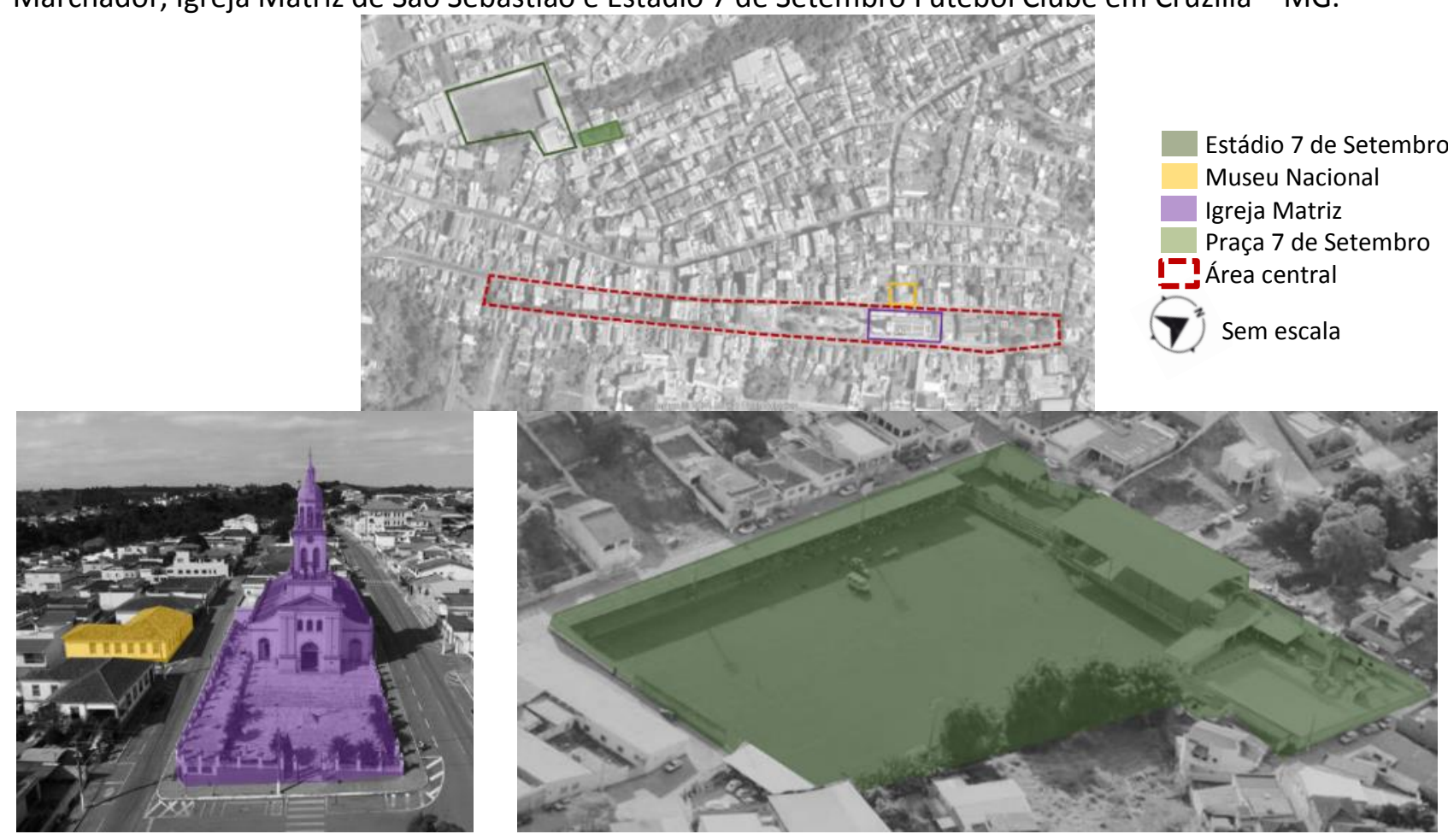

Fontes: Google Earth (2020); Mídias sociais do Clube 7 de Setembro (2020); Mídias sociais da Paróquia de São Sebastião (2020), editado pelos autores (2021).

Conforme já destacado acima, Cruzília possui cerca de 14.591 habitantes (IBGE, 2010) e, em virtude de o objetivo da pesquisa estar relacionado ao período da Primeira Infância, compreendido entre 0 e 6 anos, foram analisados alguns dados estatísticos referentes à composição da população. Na faixa etária entre 0 e 14 anos somam 3.208 pessoas, representando $22 \%$ da população total. Dessa parcela, 1.638 são do sexo feminino e 1.570 são do sexo masculino (IBGE, 2010). O destaque na análise dos dados estatísticos está na avaliação dos dados 
disponibilizados pelo IBGE (2010), e vai para a educação básica do município, que possui bons resultados, tanto no panorama estadual, quanto federal. Cruzília ocupa a 982 을 posição no país, que conta com 5570 cidades contabilizadas, devido a taxa de escolarização de crianças entre 6 e 14 anos ser de 98,7\% (IBGE, 2010).

Para atender as demandas por atividades de lazer provenientes dessa parcela entre 0 e 14 anos e de outras da população, a cidade conta com diversos espaços de lazer, públicos e privados (Figura 06). Um dos principais espaços de lazer público é a Pista de Skate USC Caike Oliveira Almeida (Figura 07), inaugurada em
7 de novembro de 2014, que não é utilizada apenas para a prática de esportes, mas também como um local para socialização, por meio de encontros e pequenos eventos. Outro espaço de lazer bastante utilizado é o Complexo Humano da Ventania (Figuras 08 e 09), que conta com um salão, onde são realizadas reuniões, formaturas e pequenos eventos, bem como uma ampla área livre e gramada, na qual comumente ocorrem leilões, copas de marchas e a tradicional festa de aniversário da cidade (PREFEITURA MUNICIPAL DE CRUZÍLIA, 2021).

Figuras 06, 07, 08 e 09- Localização da Pista de Skate USC Caike Oliveira Almeida, Salão Social e Quadra Poliesportiva do Complexo Humano da Ventania em Cruzília - MG

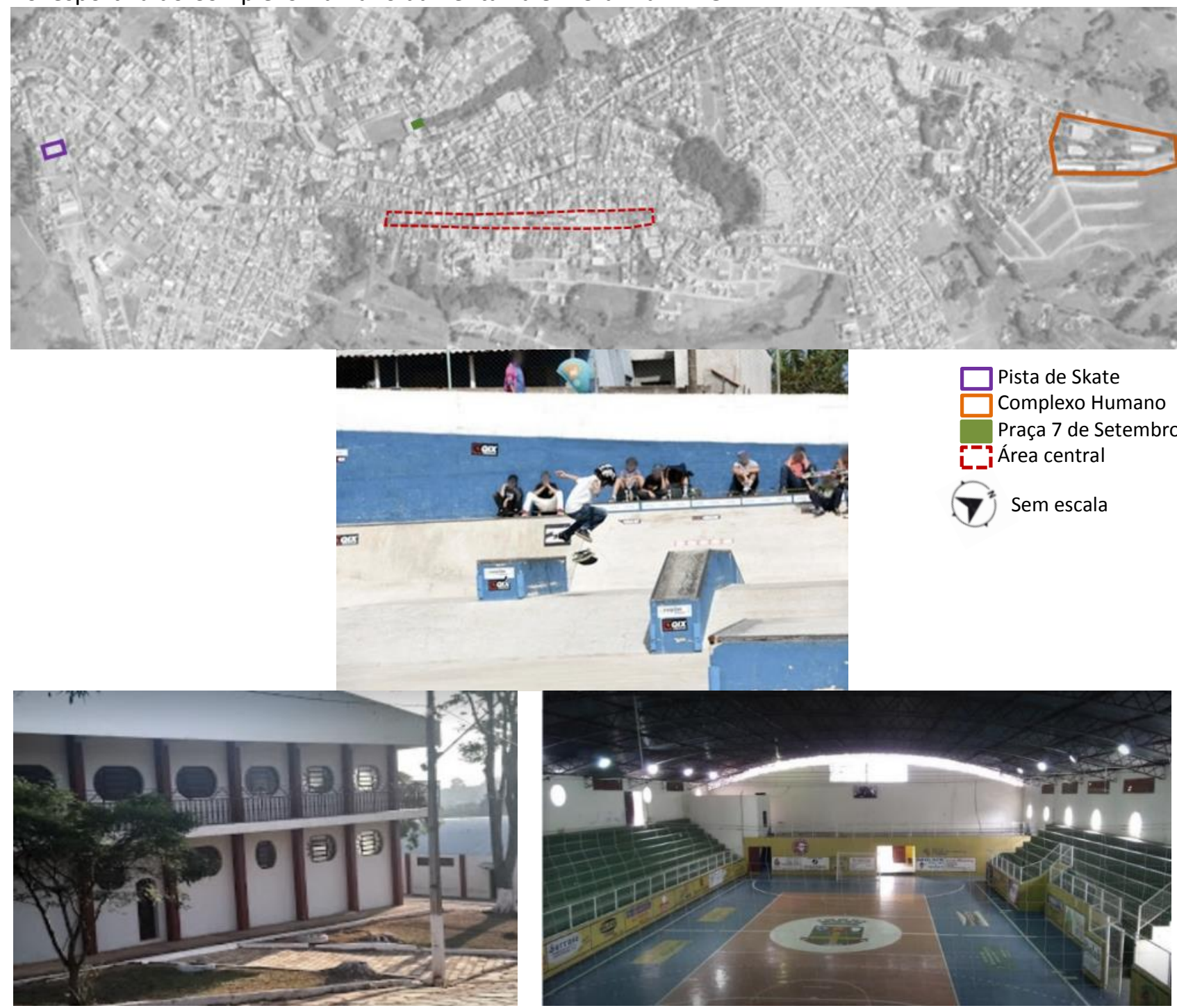

Fontes: Google Earth (2020); Prefeitura Municipal de Cruzília (2020), editado pelos autores (2021).

Há também as praças, como a Praça Capitão Maciel (Figura 10), conhecida popularmente como Praça da Matriz, sendo tombada como bem cultural pela Prefeitura Municipal de Cruzília em 2003. Por sua localização central na cidade, a praça é palco dos 
principais eventos, tanto culturais como religiosos e, aos finais de semana, é muito utilizada, principalmente devido aos brinquedos montados em seu interior (LUCENA; BARROS; SOSTER, s.d.). Outro exemplo de espaço de lazer público é a Praça 7 de Setembro (Figura 11), objeto de estudo da pesquisa, que atende, sobretudo, os moradores dos bairros próximos, além dos visitantes e sócios do Clube 7 de Setembro.

Figuras 10 e 11- Localização da Praça Capitão Maciel e Praça 7 de Setembro em Cruzília - MG.

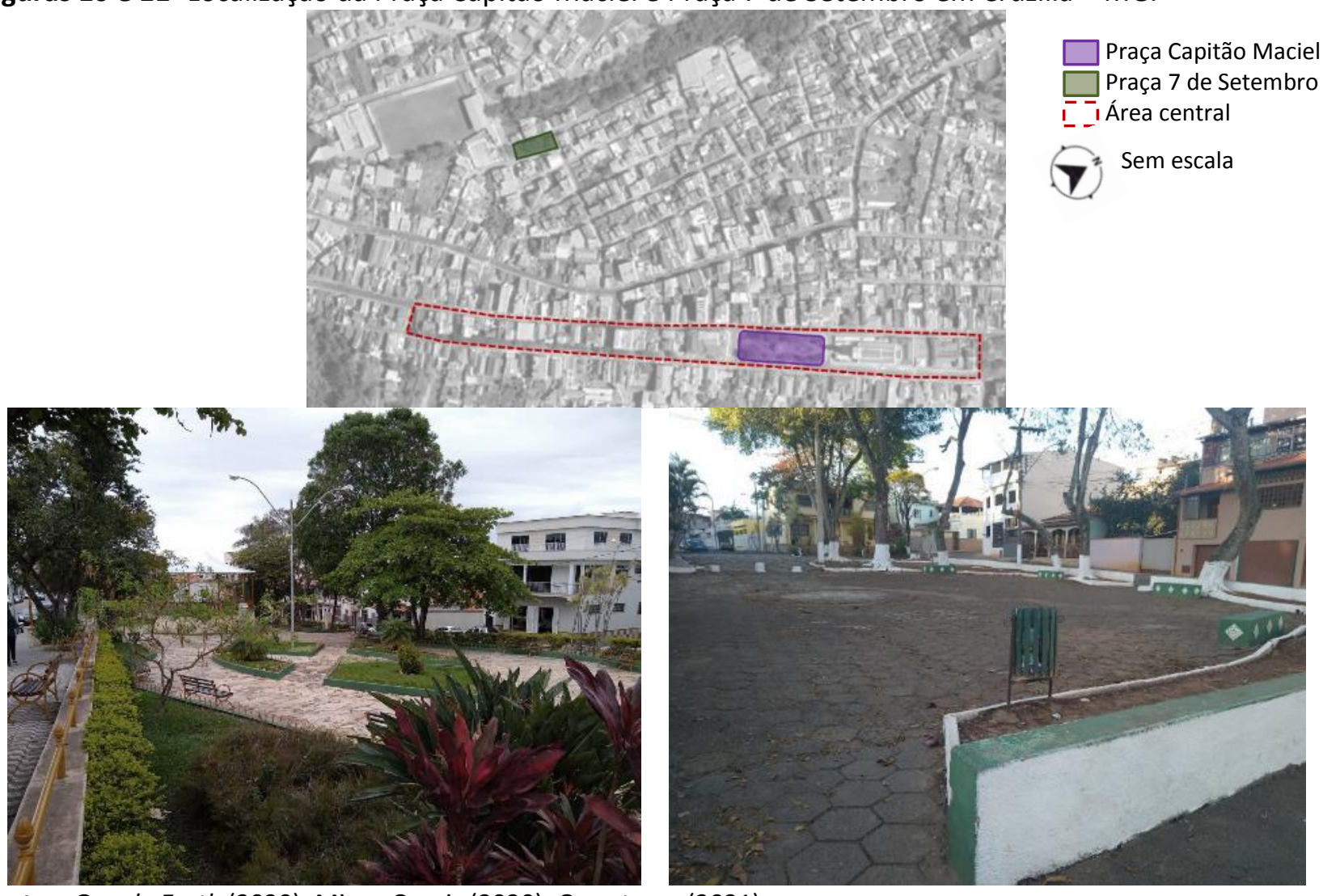

Fontes: Google Earth (2020); Minas Gerais (2020); Os autores (2021).

A Praça 7 de Setembro começou a ser construída em 1965, por meio da lei № 300 da Prefeitura Municipal, e foi finalizada e inaugurada no ano seguinte. Possui atualmente $808,15 \mathrm{~m}^{2}$, visto que em 2011 (Figura 12), parte do seu terreno foi desapropriado para a construção de uma farmácia do Programa Farmácia de Minas (Figura 13), administrada pela Secretaria de Estado de Saúde de Minas Gerais (SES/MG). A área desapropriada foi de $384,14 \mathrm{~m}^{2}$, correspondente à $200 \mathrm{~m}^{2}$ destinados à farmácia e
$184,14 \mathrm{~m}^{2}$ para uma área non aedificandi ao lado do Córrego Ribeirão Palmeira (Figura 14). Além disso, no interior do espaço público há uma rua interna, utilizada pelos transeuntes para a travessia entre a Rua João Severino Silva e a Rua João Carlos Filho, com o objetivo de oferecer maior segurança aos pedestres no deslocamento diário (PREFEITURA MUNICIPAL DE CRUZÍLIA, 2021). 
Figuras 12, 13 e 14- Localização do terreno Non Aedificandi, Córrego Ribeirão Palmeira, Farmácia de Minas e entorno da Praça 7 de Setembro em Cruzília - MG.

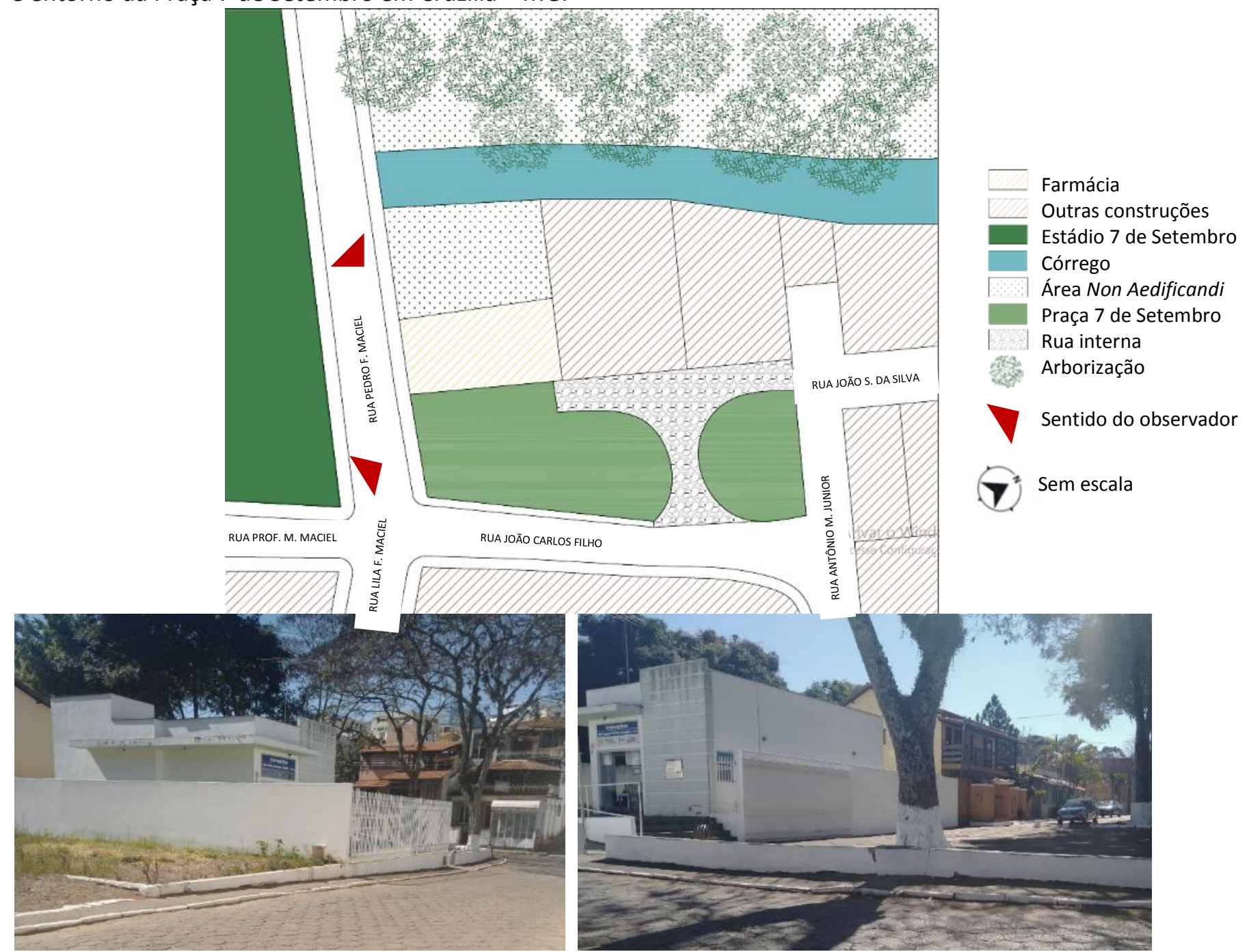

Fontes: Google Earth (2020); editado pelos autores; Os autores (2021).

Os bairros localizados no entorno da Praça 7 de Setembro são de predominância residencial. Isto faz com que ela seja um importante espaço de trocas sociais e coletivas para os moradores que residem próximos, pois muitos levam seus filhos, sobrinhos e netos para brincarem. Desse modo, é importante analisar as práticas espaciais estabelecidas atualmente nesta praça, bem como seus usos, infraestruturas e sua capacidade de oferecer ou não um espaço de qualidade aos usuários, principalmente às crianças.

\section{DISCUSSÃO}

A Praça 7 de Setembro foi inaugurada em 1966, como um espaço público de apoio ao estádio do Clube, que recebe seu mesmo nome. Desde então, os visitantes e usuários do Clube, bem como a população que reside nos bairros próximos começaram a utilizá-la para práticas de lazer, tanto no cotidiano como em atividades e eventos realizados pelo Clube, principalmente aos finais de semana (Figura 15). Além dessas atividades, a praça também já foi palco de concentrações de blocos de carnaval e celebrações religiosas. 
Figura 15- Setorização da Praça 7 de Setembro em Cruzília - MG.

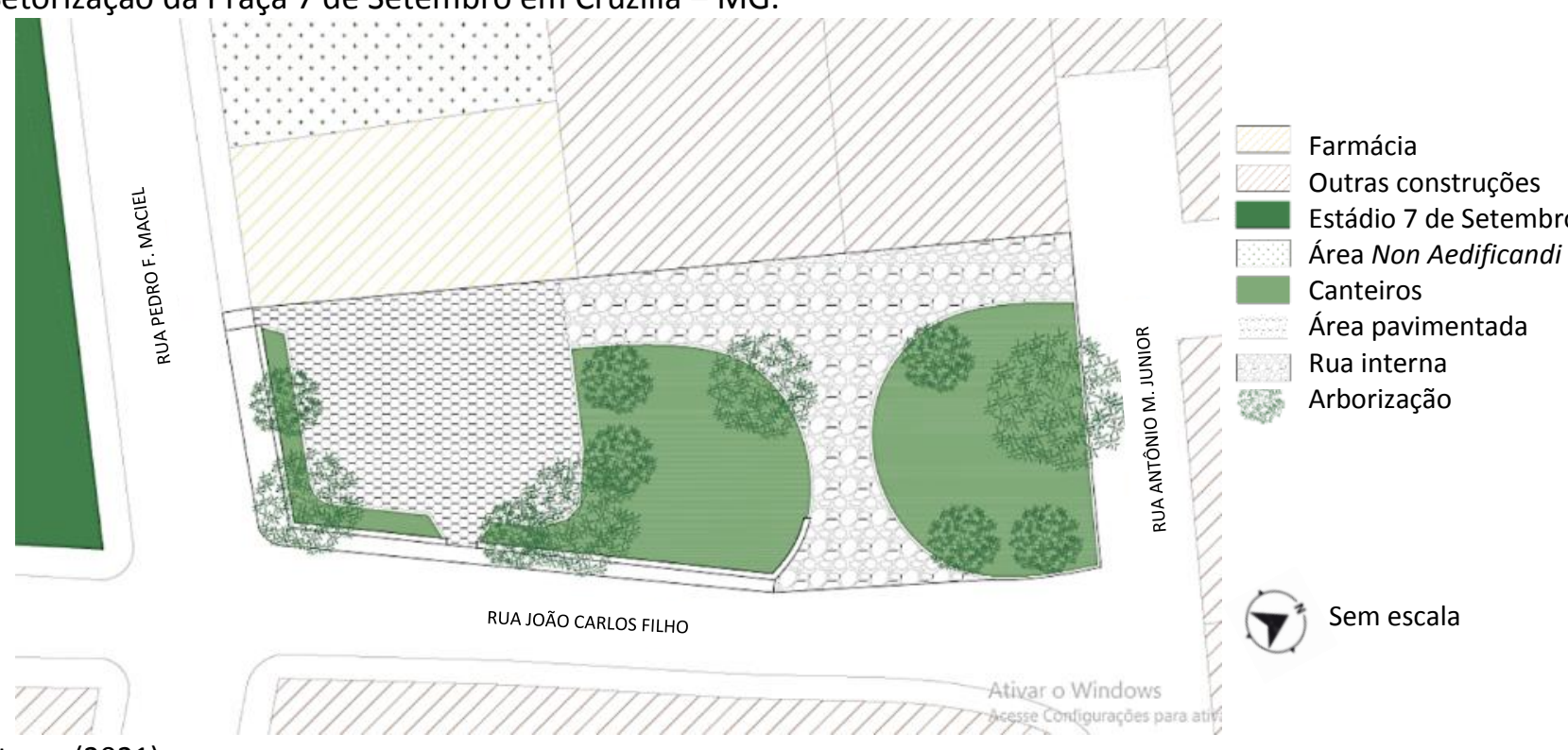

Fonte: Os autores (2021).

No entanto, foram observados durante os levantamentos in loco, reunidos em uma tabela (Tabela 1), que a praça, apesar de ser utilizada por crianças, é escassa quanto aos elementos atrativos para essa faixa etária e, igualmente, para outros públicos. Isso se dá devido a Praça 7 de Setembro possuir uma infraestrutura muito precária, em razão da falta de atrativos que deveriam ser inseridos pelo poder público, o que ocasiona a busca por outros locais para lazer e socialização. A ausência de brinquedos e mobiliários infantis ou esportivos, bem como a falta de acessibilidade e iluminação de qualidade são os principais motivos que inibem a permanência das pessoas na praça.

Tabela 01. Levantamento qualitativo e quantitativo da Praça 7 de Setembro e seus mobiliários.

\begin{tabular}{|c|c|c|c|c|}
\hline & POSSUI & QUANTIDADE & QUALIDADE & DESCRIÇÃO \\
\hline ACESSIBILIDADE & Sim & $\begin{array}{l}\text { Apenas em uma } \\
\text { parte da calçada }\end{array}$ & Ruim & $\begin{array}{l}\text { Não há piso tátil e há apenas } \\
\text { uma rampa na calçada. }\end{array}$ \\
\hline ARBORIZAÇÃO & Sim & $\begin{array}{l}\text { 10: porte médio; } \\
\text { 04: porte pequeno }\end{array}$ & Boa & $\begin{array}{c}\text { Árvores de grande porte, bom } \\
\text { sombreamento. }\end{array}$ \\
\hline ÁREAS VERDES & Sim & $41,57 \%$ & Razoável & Boa quantidade, sem cuidado. \\
\hline $\begin{array}{c}\text { ÁREAS } \\
\text { PAVIMENTADAS }\end{array}$ & Sim & $58,43 \%$ & Razoável & $\begin{array}{l}\text { Bloquete sextavado e pedra São } \\
\text { Tomé em bom estado, formação } \\
\text { de poças d'água. }\end{array}$ \\
\hline ILUMINAÇÃO & Sim & 02 postes & Razoável & Partes da praça em penumbra. \\
\hline MOBILIÁRIOS & Sim & $\begin{array}{l}04 \text { bancos; } \\
01 \text { lixeira }\end{array}$ & Razoável & $\begin{array}{l}\text { Quantidade satisfatória, mas } \\
\text { sem conforto e manutenção. }\end{array}$ \\
\hline MOBILIÁRIO EDUCACIONAIS & Não & & & \\
\hline MOBILIÁRIOS ESPORTIVOS & Não & & & \\
\hline MOBILIÁRIOS INFANTIS & Não & & & \\
\hline SINALIZAÇÃO & Sim & 01 & Razoável & $\begin{array}{l}\text { Apenas uma placa de } \\
\text { estacionamento }\end{array}$ \\
\hline
\end{tabular}

Fonte: Os autores (2021).

Foram realizados levantamentos qualitativos e quantitativos in loco, a fim de analisar as demandas e potencialidades da Praça
7 de Setembro, bem como entender as práticas espaciais e avaliar a infraestrutura ofertada, sobretudo ao público infantil. Foram classificados 
nos levantamentos suas características perante sua acessibilidade, arborização, áreas verdes e pavimentadas, iluminação, mobiliários e sinalização. A partir desses levantamentos foram constatados os seguintes aspectos da Praça 7 de Setembro:

Quanto à acessibilidade, não possui nenhum tipo de piso tátil, dificultando o acesso de pessoas com deficiências visuais sem acompanhantes, o que diminui a autonomia desse grupo no espaço público (Figura 16). Ademais, a praça possui apenas uma rampa de acesso na calçada (Figura 17), assim a entrada de adultos e crianças com deficiências locomotoras é bastante difícil, sendo necessário que a pessoa percorra boa parte do perímetro da praça até sua rua interna para ter acesso à mesma. A calçada de todo seu contorno é estreita, com $50 \mathrm{~cm}$ de largura (Figura 18), sendo impossível que duas pessoas andem lado a lado pelo passeio, ou mesmo a travessia com cadeira de rodas, e, portanto, não são atendidas as recomendações da NBR 9050 (2020).

Figuras 16, 17 e 18- Localização da rampa de acesso e calçada da Praça 7 de Setembro em Cruzília - MG.

Fonte: Os autores (2021).

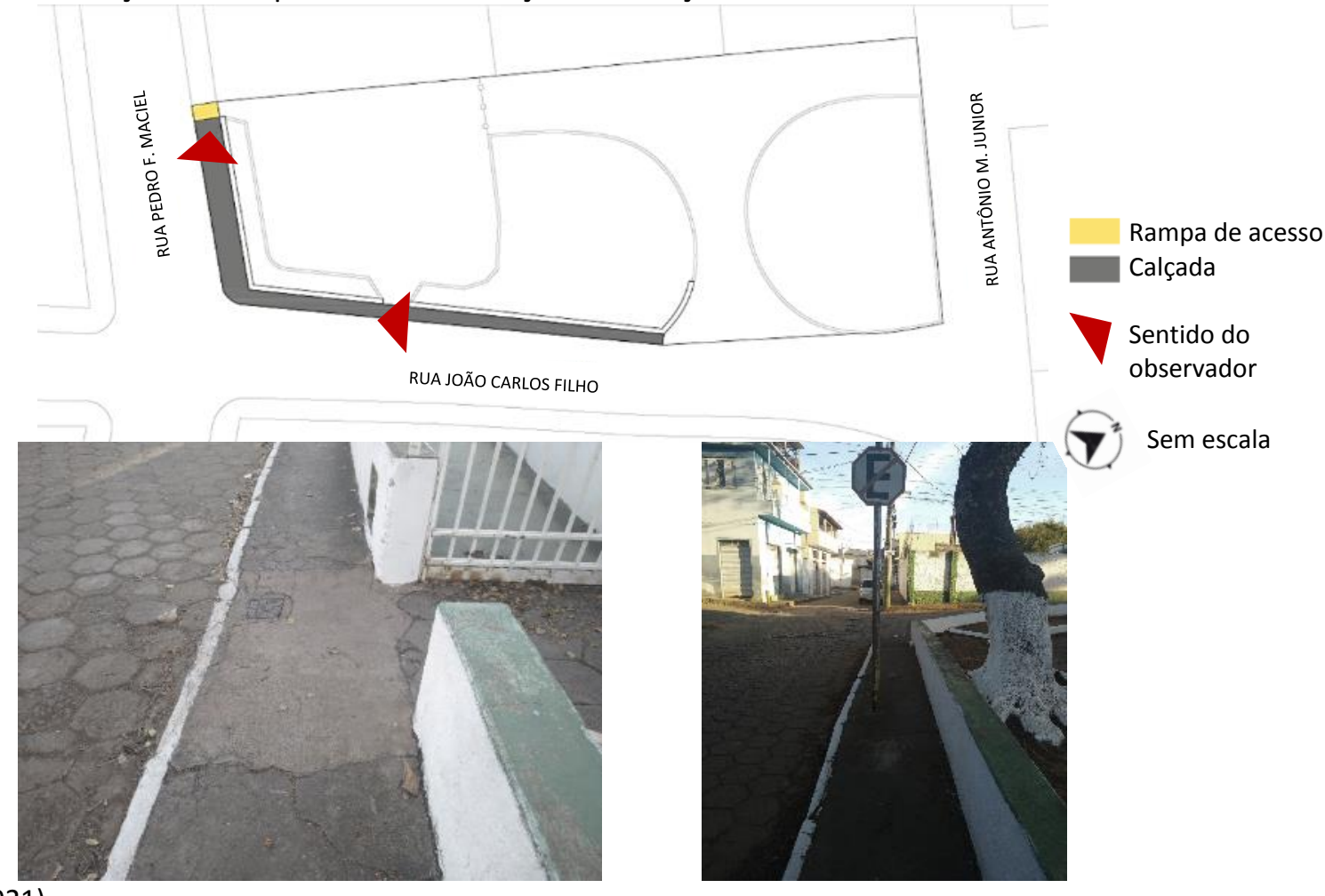

A Praça 7 de Setembro contém áreas gramadas e pavimentadas (Figura 19), mas ambas necessitam de reparos. Apesar de um número razoável de áreas verdes, somando $41,57 \%$ da área total da praça (Figura 20), o gramado não recebe constantes manutenções e, mesmo sendo um dos locais ideais para as crianças desenvolverem suas brincadeiras, isto torna-se inviável pela falta de qualidade. A pavimentação é de dois tipos de materiais: os bloquetes sextavados e as pedras São Tomé (Figura 21), muito comuns e abundantes na região. Porém, em épocas de chuva, há intensa formação de poças d’água no interior do espaço público, tornando-o inutilizável quando não há estiagem da chuva. 
Figuras 19, 20 e 21- Localização das áreas verdes e pavimentadas da Praça 7 de Setembro em Cruzília - MG.

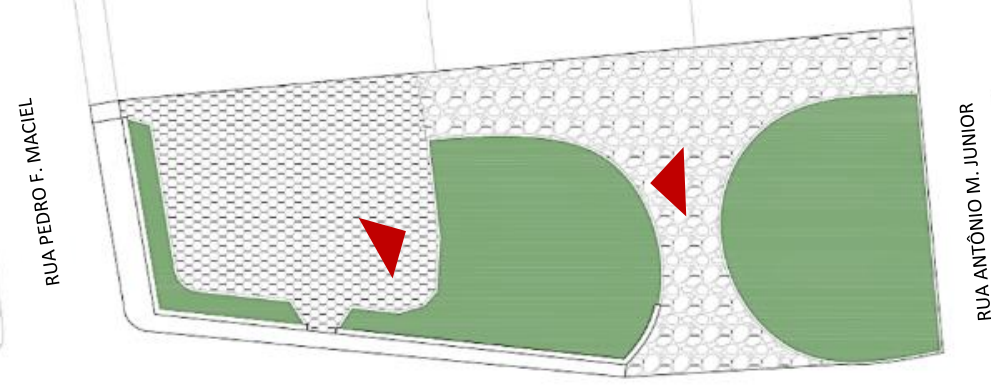

RUA JOÃO CARLOS FILHO

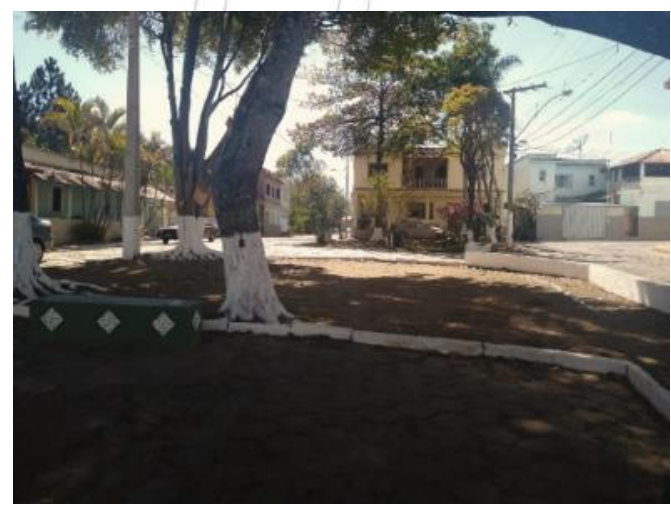

Fonte: Os autores (2021).

O espaço público estudado não possui nenhum tipo de mobiliário esportivo ou infantil, o que gera uma menor permanência das crianças e, quando vão à Praça 7 de Setembro, é necessário que elas levem seus próprios brinquedos, como bolas, bicicletas e jogos de tabuleiro, limitando as possibilidades de brincadeiras. Foi observado também que, pela ausência de playgrounds ou brinquedos fixos, as crianças utilizam a

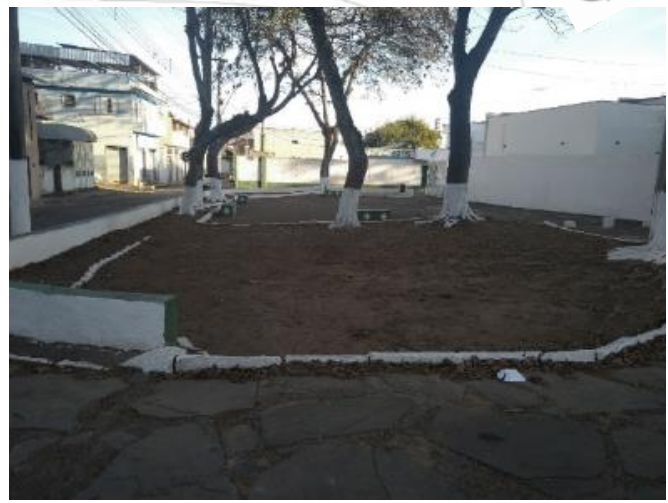

criatividade para brincarem com o que há disponível no espaço (Figuras 22 e 23), como os bancos de concreto e as muretas que contornam a praça, porém são brincadeiras arriscadas e, que podem resultar em possíveis acidentes, pois as crianças pulam entre esses mobiliários e elementos construtivos.

Figuras 22 e 23. Crianças brincando na Praça 7 de Setembro em Cruzília - MG.

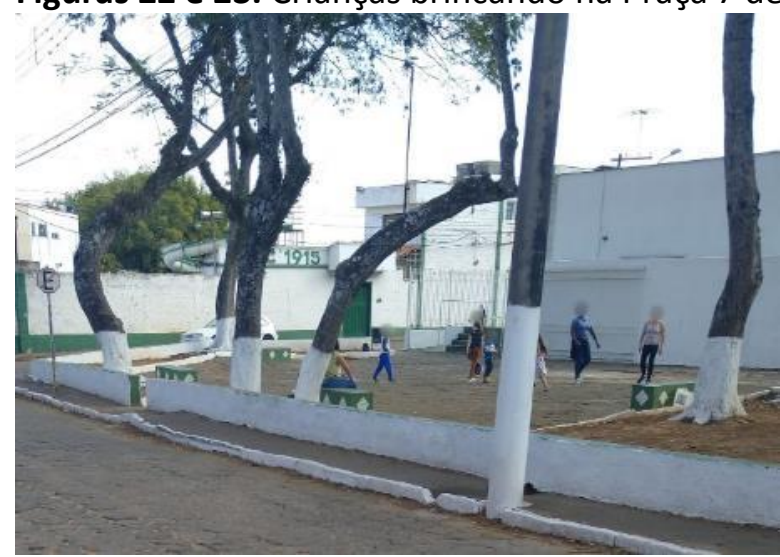

Fonte: Os autores (2021).

A iluminação é outro ponto bem crítico do espaço público, que possui apenas 02 postes em seu interior (Figura 24). Apesar do pouco

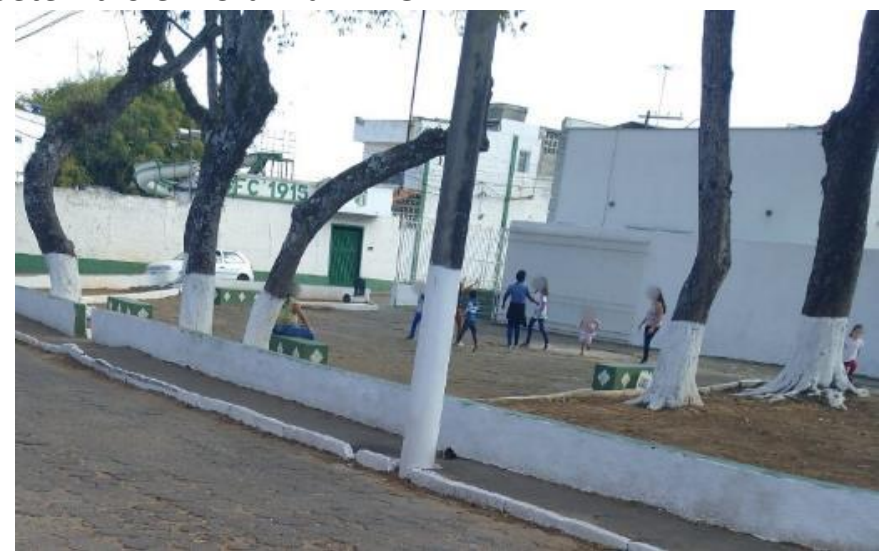

espaço interno da Praça 7 de Setembro, algumas áreas da mesma ficam em penumbra durante o período noturno (Figuras 25 e 26), sendo mais um 
motivo que impede a permanência das pessoas na praça, por medo de acontecer algum ato de violência. A sinalização da praça ou próxima a ela também não é satisfatória, onde existe apenas uma placa de proibição de estacionamento na Rua João Carlos Filho.

Figuras 24, 25 e 26- Iluminação e penumbras às 20h na Praça 7 de Setembro em Cruzília - MG.
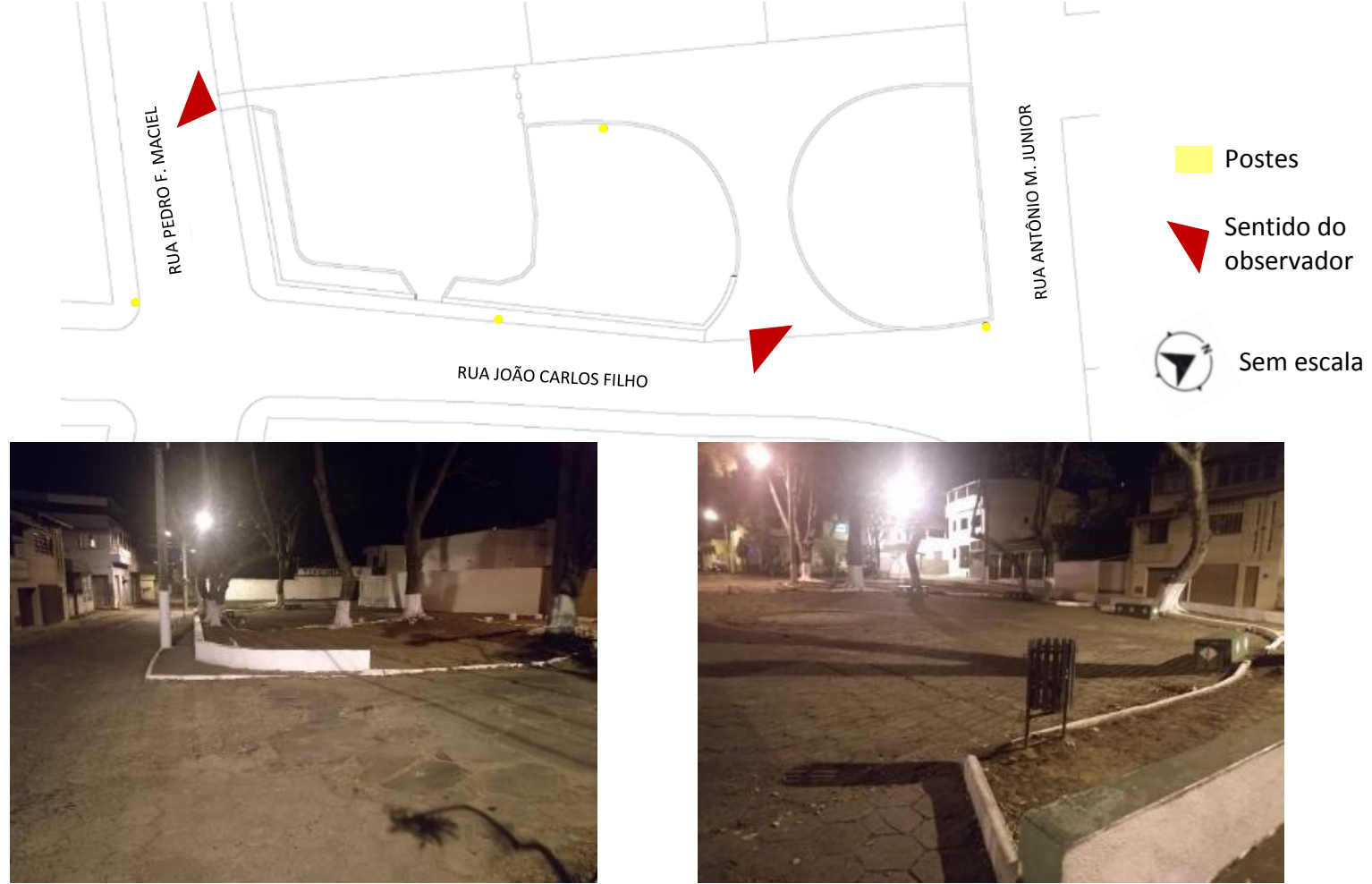

Fonte: Os autores (2021).

Além da falta de mobiliários infantis e esportivos, o espaço público conta com apenas 04 bancos (Figura 27), todos eles confeccionados em concreto e pintados na cor verde, nenhum deles possui encosto e acabam sendo desconfortáveis (Figura 28). Possui ainda apenas uma lixeira (Figura 29), que faz com que os usuários do espaço público necessitem andar quase toda sua extensão até chegar ao local de destinação do lixo, sendo recolhido semanalmente pelos agentes de limpeza urbana da cidade.

Figuras 27, 28 e 29- Bancos e lixeira da Praça 7 de Setembro em Cruzília - MG.

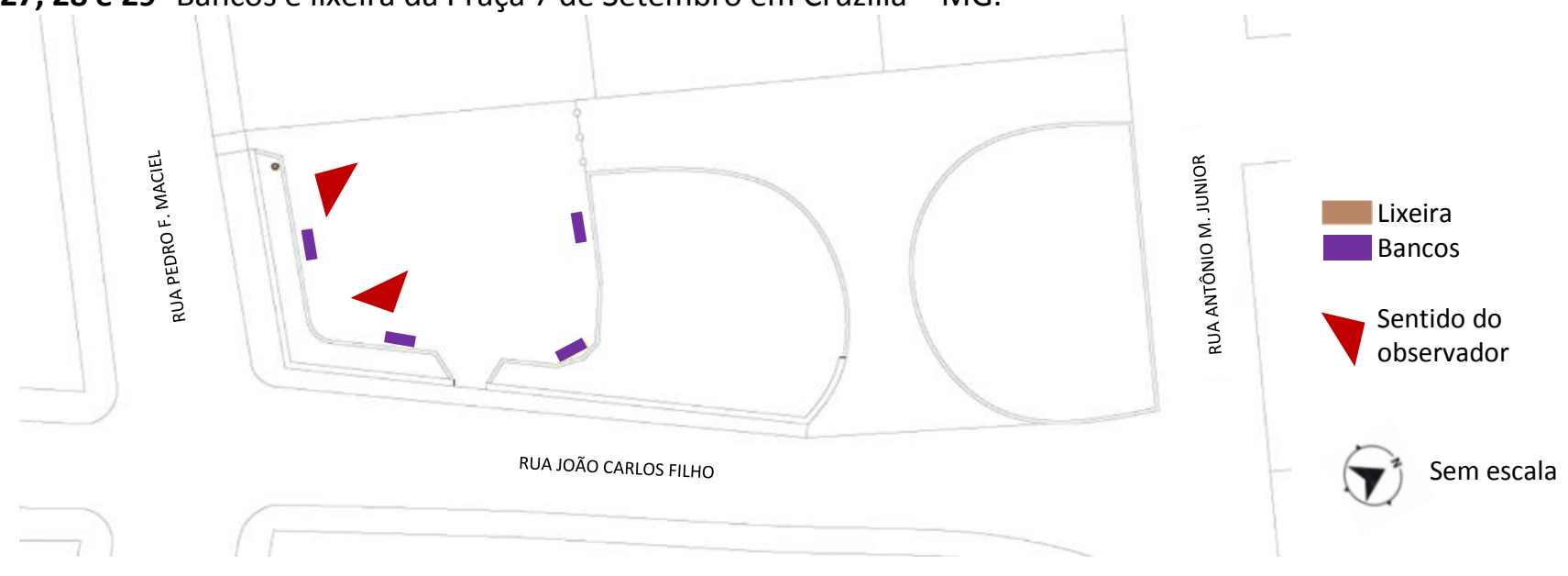




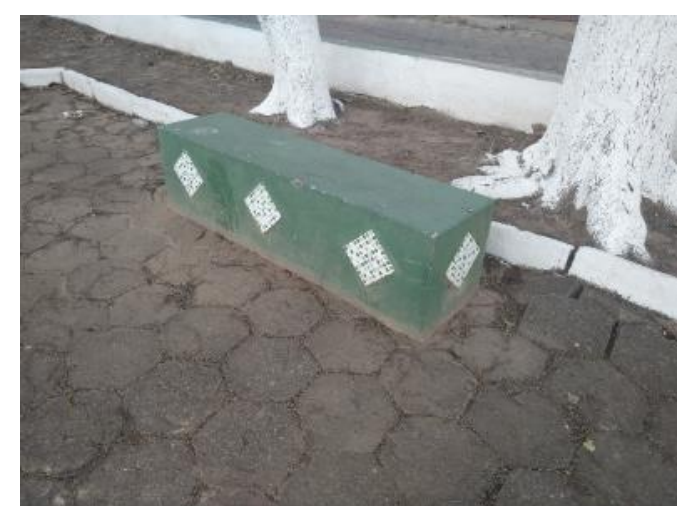

Fonte: Os autores (2021).

O ponto mais satisfatório da Praça 7 de Setembro é com relação à sua arborização: foi constatada a presença de 14 árvores no total, sendo que 10 delas são de porte médio e 04 delas de porte pequeno, todas já na fase adulta. Por conta dessas características, o espaço público possui uma área sombreada satisfatória (Figura 30), que permite um bom aproveitamento do

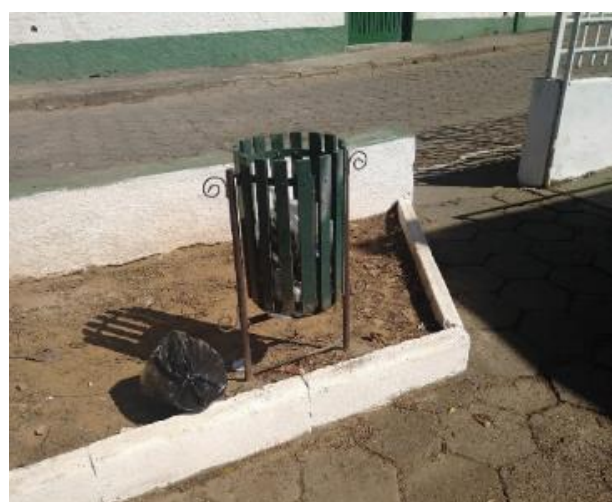

espaço em horários de maior incidência solar. Ademais, são realizadas podas periódicas dos galhos a fim de mitigar possíveis acidentes (Figura 31 ), causados principalmente pelas intempéries, como chuvas e ventos.

Figuras 30 e 31- Áreas sombreadas e poda realizada no dia 11/06/2021 na Praça 7 de Setembro em Cruzília - MG.
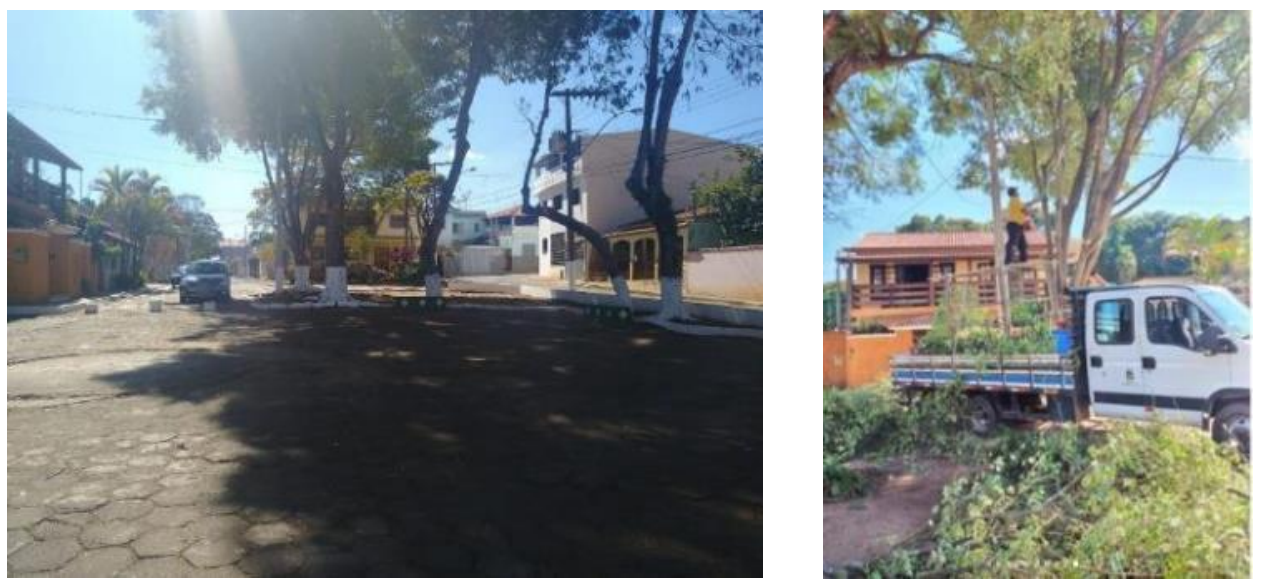

Fontes: Os autores (2021); Mídias sociais da Prefeitura Municipal (2021).

Durante a realização dos levantamentos in loco, além das análises qualitativas e quantitativas com relação à infraestrutura da Praça 7 de Setembro, também foram analisadas as questões referentes às práticas espaciais, tais como os períodos de maior utilização, as atividades realizadas e as condições para sua execução, bem como as relações de pertencimento entre os usuários e o espaço público, prezando sempre pelo vínculo entre criança e praça.

A principal característica observada quanto aos períodos de uso do espaço público foi que, no período noturno, a Praça 7 de Setembro praticamente não é frequentada, servindo somente como um "atalho" de passagem entre as ruas Pedro F. Maciel e João Carlos Filho. Foi observado que, esta falta de uso da praça é resultado, sobretudo, da falta de iluminação adequada para a área, pois como abordado, o número reduzido de postes não é suficiente para uma completa iluminação, resultando que ocorram áreas de penumbra no interior do espaço público. Isso faz com que os pais e responsáveis optem por levar as crianças a outras praças no período noturno, devido à maior iluminação e segurança.

O período mais frequentado pelas 
crianças é o matutino, principalmente entre $9 \mathrm{~h}$ e $10 \mathrm{~h}$ da manhã, e meados do período vespertino, a partir das $15 \mathrm{~h}$ até o final do entardecer. Isso se dá devido às melhores condições climáticas, pois nesses horários a incidência solar não é muito intensa, logo a permanência no local é mais agradável. Além disso, em decorrência do movimento solar, o interior do espaço público nesses horários é mais sombreado, por conta das árvores ali presentes.

Para as análises de uso do espaço público, foram elencadas com maior destaque as atividades realizadas por crianças, por estas serem o foco da pesquisa. Observou-se que, pela ausência de equipamentos de lazer infantil, as crianças levam seus próprios brinquedos, como bicicletas e bolas, como já citado anteriormente. Porém, as brincadeiras que necessitam apenas da criatividade dos usuários é que são as mais realizadas, como o pega-pega (Figuras 32 e 33) e também a travessia entre os elementos fixos presentes na Praça 7 de Setembro, como as muretas e bancos que, apesar de estimularem a criatividade da criança, são brincadeiras arriscadas e perigosas. Comumente os adultos frequentam a praça para supervisionar as crianças levadas ao local, ou apenas para passagem entre os percursos cotidianos.
Figuras 32 e 33- Crianças brincando de pega-pega na Praça 7 de Setembro em Cruzília - MG.

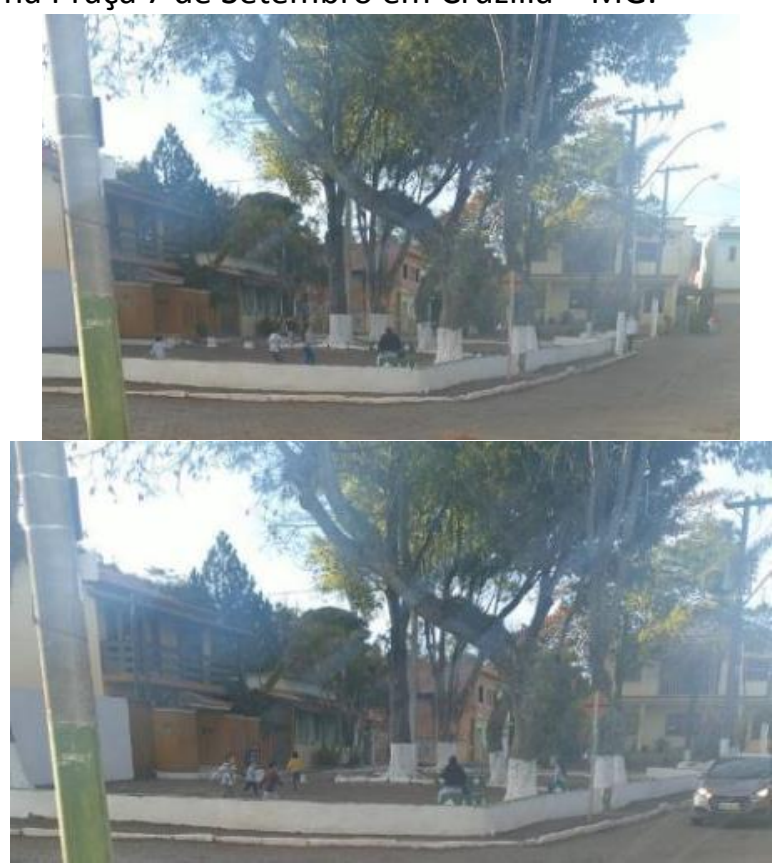

Fontes: Os autores (2021).

Constatou-se então durante a realização dos levantamentos in loco que as relações de pertencimento entre as crianças e o espaço público são bastante afetadas, sobretudo pela ausência de atrativos, tanto com relação aos brinquedos e à infraestrutura, quanto à estética da praça, que não possui nenhuma pintura lúdica ou que chame atenção do público infantil (Figuras 34 e 35). Desse modo, as crianças ou mesmo seus responsáveis optam por frequentar outras praças, que ofereçam tais atrativos citados.

Figuras 34 e 35- Área interna da Praça 7 de Setembro em Cruzília - MG, sem nenhum atrativo voltado para o público infantil.

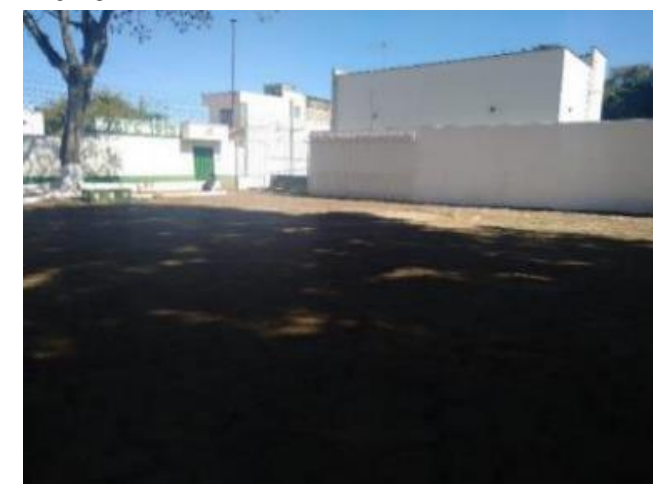

Fontes: Os autores (2021)

Em síntese, observou-se que a Praça 7 de Setembro, apesar de ser frequentada por crianças, não oferta uma infraestrutura de qualidade, não possui mobiliários esportivos ou

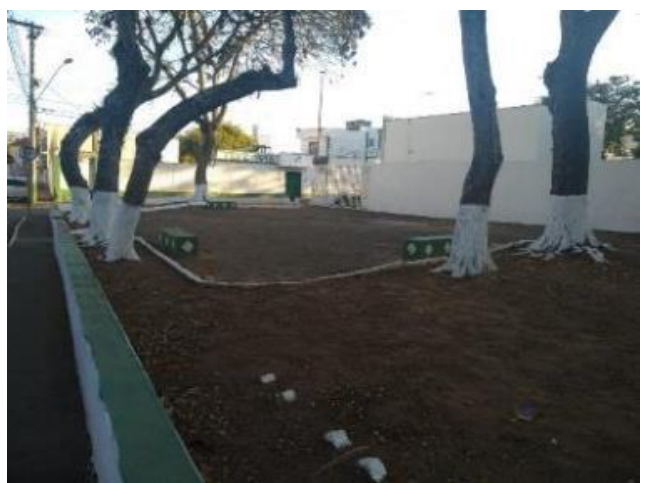

infantis e nem mesmo possui elementos atrativos para o público infantil, assim o espaço público não é conveniente para a presença de crianças, em comparação com outras praças existentes em 
Cruzília, mais comumente utilizadas pelas crianças.

Por meio das leituras urbanas, das análises in loco e das revisões bibliográficas realizadas, é importante compreender o papel da primeira infância na concepção de um meio urbano mais inclusivo e socialmente favorável a todas as pessoas, sobretudo ao público infantil. As crianças devem ter sua cidadania assegurada, através de políticas públicas que visem o seu desenvolvimento em todos os níveis, seja cultural, histórica ou socialmente. Meira (2011) explica que, assim como a própria cidade, os espaços públicos também devem ser pensados a fim de atender as demandas do público infantil, pois eles são os principais transformadores e propagadores de novas experiências sociais a esses pequenos usuários.

Durante a pesquisa, foi observado que existem desafios, pois os espaços públicos em geral apresentam muitas falhas projetuais, assim como o espaço público que foi objeto de estudo, o qual possui muitas problemáticas responsáveis por influenciar as relações de pertencimento e de memória coletiva do local e, apesar das características negativas apontadas nas análises, há potencialidades que podem ser exploradas.

A praça é antiga, fundada em 1968 e já foi palco de diversos tipos de usos, mas mesmo assim, ainda necessita de um projeto completo de requalificação, a fim de torná-la mais atrativa não só para as crianças, mas também para o público em geral. Tal iniciativa deve partir do poder público, ou mesmo da própria população, para em conjunto avaliarem as demandas e as práticas espaciais a fim de elaborar um projeto urbano que vise a estética e a funcionalidade, bem como a continuidade das que já ocorrem na Praça 7 de Setembro.

\section{REFERÊNCIAS}

ANDRADE, C. D. A pequena Cruzília. Jornal do Brasil. Em 20 de março 1973. Disponível em: www.descubraminas.com.br. Acesso em: 14 jul. 2021.

ASOCIACIÓN INTERNACIONAL DE CIUDADES EDUCADORAS. Ciudad Educadora. 2012. Disponível em: http://www.bcn.cat/edcities/aice/estatiques/esp anyol/sec_educating.html. Acesso em: 03 maio 2021.
ASSOCIAÇÃO BRASILEIRA DE NORMAS TÉCNICAS. NBR 9050: Acessibilidade a edificações, mobiliário, espaços e equipamentos urbanos. Rio de Janeiro: ABNT, 2015.

BRASIL. Decreto № 8.869 , de 05 de outubro de 2016. Institui o Programa Criança Feliz. Programa Criança Feliz. Diário Oficial [da] República Federativa do Brasil, Brasília, DF, 05 out. 2016. Disponível

em:http://www.planalto.gov.br/ccivil_03/_Ato20 15-2018/2016/Decreto/D8869.htm. Acesso em: 14 jul. 2021.

BRASIL. Emenda constitucional № 10.257, de 10 de julho de 2001. Regulamenta os arts. 182 e 183 da Constituição Federal, estabelece diretrizes gerais da política urbana e dá outras providências. Estatuto da Cidade. Diário Oficial [da] República Federativa do Brasil, Brasília, DF, 11 jul. 2001. Disponível em: http://www.planalto.gov.br/ccivil_03/LEIS/LEIS_2 001/L10257.htm. Acesso: 05 maio 2021.

BRASIL. Ministério da Cidadania. Programa Criança Feliz.[2019?]. Disponível em: https://www.gov.br/cidadania/pt-br/acesso-ainformacao/carta-de-servicos/desenvolvimentosocial/promocao-do-desenvolvimento-

humano/programa-crianca-feliz-1. Acesso em: 14 jul. 2021.

CIRCUITO DAS ÁGUAS MG, Cruzília. [c2021]. Disponível em: https://circuitodasaguasmg.com.br/. Acesso em: 14 jun. 2021.

GADELHA, J. B. Instrumentos projetuais de Arquitetura e Urbanismo como agentes transformadores, tendo como parâmetro a escala da criança. In: COLÓQUIO INTERNACIONAL IMAGINÁRIO: CONSTRUIR E HABITAR A TERRA / DEFORMAÇÕES, DESLOCAMENTOS E DEVANEIOS (ICHT), 3. , 2019, São Paulo. Anais [...]. São Paulo: USP, 2019. Disponível em: https://sites.usp.br/icht2019/wpcontent/uploads/sites/416/2019/07/Instrumento s-projetuais-de-Arquitetura-e-Urbanismo-comoagentes-transformadores-tendo-comopara\%CC\%82metro-a-escala-da-crianc\%CC\%A7a.pdf. Acesso em: 03 jun. 2021. 
GARCIA, C. Bienal de educação em arquitetura discute participação das crianças no espaço público. 2018. Disponível em: https://portal.aprendiz.uol.com.br/2018/03/02/b ienal-de-educacao-em-arquitetura-discuteparticipacao-das-criancas-no-espaco-publico/. Acesso em: 14 jul. 2021.

IBGE. Censo demográfico. 2010. Disponível em: https://cidades.ibge.gov.br/brasil/mg/cruzilia/pe squisa/39/30279. Acesso em: 18 maio 2021.

LOEB, R. M. Territórios Vulneráveis, Arquitetura e Urbanismo: estratégias contemporâneas de ação. 2019. Dissertação (Mestrado em Arquitetura e Urbanismo) - Universidade Presbiteriana Mackenzie, São Paulo, SP, 2019.

LUCENA, C. C.; BARROS, C.; SOSTER, S. S. Patrimônio. Cruzília: Praça Capitão Maciel, Disponível em: http://www.ipatrimonio.org/cruzilia-pracacapitao-maciel/\#!/map=38329\&loc=-21.839069,44.808863,17. Acesso em: 17 jun. 2021.

LUKE, N.; TALK, R.; SAMIOS, A.; STEIL, C. A. Como desenhar espaços urbanos mais seguros $\mathrm{e}$ saudáveis para as crianças. 2020. ArchDaily Brasil. Disponível em: https://www.archdaily.com.br/br/949972/comodesenhar-espacos-urbanos-mais-seguros-esaudaveis-para-criancas. Acesso em: 03 maio 2021.

LUZ, G. M. da; KUHNEN, A. O uso dos espaços urbanos pelas crianças: explorando 0 comportamento do brincar em praças públicas. Psicologia: Reflexão e Crítica, v. 26, p. 552-560, $2013 . \quad$ https://doi.org/10.1590/S010279722013000300015

MEIRA, A. M. Olhares das crianças sobre a cidade de Porto Alegre: infância contemporânea, psicanálise, educação e arte. 2011. Dissertação (Doutorado em Educação) - Faculdade de Educação, Universidade Federal do Rio Grande do Sul. Porto Alegre, 2011.

MERLIN, J. R.; QUEIROZ, A. N. Espaços Públicos: suas potencialidades educadoras e a construção da cidadania. In: ENCONTRO DA ASSOCIAÇÃO NACIONAL DE PESQUISA E PÓS-GRADUAÇÃO EM ARQUITETURA E URBANISMO, 3. , 2014, São Paulo. Arquitetura, cidade e projeto: uma construção coletiva. Anais [...]. [S. I.]: ANPARQ, 2014. Disponível em:

https://www.anparq.org.br/dvd-enanparq-

3/htm/Artigos/SC/ORAL/SC-EPC-

034_MERLIN_QUEIROZ.pdf. Acesso em: 03 maio 2021.

PEREIRA, Larissa de Souza; PARISI, Rosana Soares Bertocco. Fazendas do sul de Minas Gerais no Brasil: possibilidades de preservação e gestão. In: Tierra, sociedad, comunidad: $15^{\circ}$ Seminario Iberoamericano de Arquitectura y Construcción con Tierra. Universidad de Cuenca, 2015. p. 399410.

PREFEITURA MUNICIPAL DE CRUZÍLIA. História da Cidade de Cruzília. Disponível em: http://www.cruzilia.mg.gov.br/site/index.php/hist oria. Acesso em: 14 jul. 2021.

PREFEITURA MUNICIPAL DE CRUZÍLIA. Lei № 1.908, de 30 de junho de 2009. Institui o Plano Diretor do Município de Cruzília e dá outras providências. Plano diretor de Cruzília. Cruzília, MG: Prefeitura Municipal de Cruzília, , 2009.

ROCHA, B. N. da; COSTA, C. A. da; LAGO, F. C.; ARUDA, J. M. P. de; ABREU, P. G.; SCHUMACGER, C.; KRUEL, C. S.; GUAZINA, F. M. N.; CARLESSO, J. P. P. Crianças no espaço público: contribuições para um desenvolvimento saudável. Research, Society and Development, n. 8, 2018. Disponível em:

https://rsdjournal.org/index.php/rsd/article/view /595/650+t>. Acesso em: 03 maio 2021.

SARMENTO, M. J. Apresentação do Dossiê Crianças e suas infâncias na cidade. Cadernos de Pesquisa em Educação, Vitória, v. 21, n. 49, p. 1-5, jan./jun. 2019. https://doi.org/10.22535/cpe.v21i49.26179 